\title{
Two Cases of Cutaneous Squamous Cell Carcinoma Arising in Immunosuppressed Patients with Chronic Human Papillomavirus Infection
}

\author{
Yuki Kuma ${ }^{a}$ Takamichi Ito $^{a}$ Konosuke Nagae $^{a}$ Yukihiro Mizote $^{a}$ \\ Takeshi Nakahara $^{a}$ Hiroshi Uchi $^{a}$ Yuichi Yamada ${ }^{b}$ Masae Okura ${ }^{c}$ \\ Yoshinao Oda $^{b}$ Toshiharu Yamashita $^{c}$ Masutaka Furue ${ }^{a}$ \\ Departments of ${ }^{a}$ Dermatology and ${ }^{b}$ Anatomic Pathology, Graduate School of Medical \\ Sciences, Kyushu University, Fukuoka, and 'Department of Dermatology, Sapporo Medical \\ University School of Medicine, Sapporo, Japan
}

\section{Key Words}

Squamous cell carcinoma · Actinic keratosis · Human papilloma virus · PCR · Immunosuppressed patients · Histopathology

\begin{abstract}
Increasing evidence has suggested that human papillomaviruses (HPVs) are linked to a large subset of numerous malignant tumors, including mucosal squamous cell carcinoma (SCC); however, its involvement in cutaneous SCC has not fully been elucidated. Cutaneous SCC is the second most common type of skin cancer and is increasing in frequency every year. Since we have no satisfactory treatment for advanced SCC, it is important to provide a definitive diagnosis and appropriate therapeutic intervention at an early stage. Here, we present two cases of SCC arising in immunosuppressed patients. In these cases, we suspected the association between SCC and HPV infection histopathologically and succeeded in proving the presence of high-risk type HPV by PCR analysis (HPV 14 in case 1 and HPV 23 and 38 in case 2). Although it is unclear whether HPV actually induced SCC in our cases, our cases showed rapid progression comparing to typical courses of actinic keratosis (AK)/SCC. SCC and AK are common diseases; in daily practice, dermatologists examine many patients with immunosup-
\end{abstract}

KARGER 125/s $\quad \begin{aligned} & \text { Yuki Kuma } \\ & \text { Department of Dermatology } \\ & \text { Graduate School of Medical Sciences, Kyushu University } \\ & 3-1-1 \text { Maidashi, Higashiku, Fukuoka 812-8582 (Japan) } \\ & \text { E-Mail yukikuma@dermatol.med.kvushu-u.ac.jp }\end{aligned}$


Kuma et al.: Two Cases of Cutaneous Squamous Cell Carcinoma Arising in Immunosuppressed Patients with Chronic Human Papillomavirus Infection

pression of various causes. We should apply increased oncological vigilance to these patients to prevent an aggressive course of SCC/AK.

(c) 2015 S. Karger AG, Basel

\section{Introduction}

Squamous cell carcinoma (SCC) is the second most common type of skin cancer and is increasing in frequency every year [1,2]. Since we have no fully effective treatment for advanced SCC, it is important to provide a definitive diagnosis and appropriate therapeutic intervention at an early stage. Ultraviolet radiation exposure, fair skin and an immunosuppressed condition are well-known risk factors for the development of SCC [2]. In recent years, increasing evidence has suggested that human papillomaviruses (HPVs) are linked to a large subset of numerous malignant tumors, including cutaneous SCC [3-5]. Here, we present two cases of HPV-related SCC arising in immunosuppressed patients. In these cases, the association of HPV was suspected histopathologically.

\section{Case Presentation}

\section{Case 1}

A 43-year-old Japanese female presented with a 1-year history of a rapidly growing mass on the head. Multiple sites of keratotic erythema were noted around this mass (fig. 1a). She had been receiving immunosuppressant treatment with tacrolimus (1 mg/day) for 6 years because she had undergone a kidney transplant due to renal failure secondary to idiopathic nephrotic syndrome. After obtaining a diagnosis of SCC with multiple actinic keratoses (AKs) by skin biopsy, we resected the tumor together with the surrounding AKs because keratinocytes of an AK lesion showed cytoplasmic vacuolization, suggesting HPV involvement (fig. 1b). Histopathological examination of the resected specimen revealed the proliferation of atypical keratinocytes with hyperkeratosis, parakeratosis and papillomatosis, which indicated SCC arising in AK. PCR analysis of the paraffin-embedded sample confirmed the presence of HPV 14.

\section{Case 2}

An 82-year-old Japanese female presented with disseminated keratotic papules and erythema on the face, forearms and hands (fig. 2a). The lesions were restricted to the sunexposed areas and had been rapidly growing. The patient had been suffering from adult Tcell leukemia and had undergone immunosuppressant treatment with prednisolone at 7.5 $\mathrm{mg}$ /day for about 10 years. She had no family history of epidermodysplasia verruciformis. We excised as many of these lesions as possible. Histopathological examination of a facial lesion showed the findings of SCC with AK. Because mild cytoplasmic vacuolization was observed in the adjacent epidermal cells (fig. 2b), we performed PCR analysis and detected HPV 23 and HPV 38.

\section{Discussion}

The long-term use of immunosuppressive agents is one of the risk factors for the development of SCC [6]. The immunosuppressive doses of our cases were tacrolimus $1 \mathrm{mg} /$ day in case 1 and prednisolone $7.5 \mathrm{mg} /$ day in case 2; the intensity of immunosuppression was rela- 
Kuma et al.: Two Cases of Cutaneous Squamous Cell Carcinoma Arising in Immunosuppressed Patients with Chronic Human Papillomavirus Infection

tively low compared to the standard maintenance dose of post organ transplantation or the common dose of prednisolone [7]. Besides these carcinoma-predisposing conditions, it is of interest that HPVs were detected in our cases. HPVs are a family of small double-stranded DNA viruses that have tropism for the mucosa of the genital and upper respiratory tracts and for the skin. Approximately 150 HPV types have been discovered so far, and they are classified into several genera based on their DNA sequences. The presence of HPV E6 and E7 oncoproteins in the epidermis is essential for the development of cervical cancer [4], Bowen's disease [8] and ultraviolet radiation-induced skin cancers in the mouse model [9]. The role of HPV in the induction and maintenance of mucosal SCC is well recognized, but its role in cutaneous SCC remains to be elucidated. Recent studies have focused on viral activity in addition to DNA presence, and HPV is thought potentially to play a role in the induction of cutaneous SCC by acting as a cocarcinogen [5]. Additionally, HPV induces epithelialmesenchymal transition-like processes, possibly contributing to tumor progression and metastasis [10]. In our cases, we suspected the association between SCC/AK and HPV infection histopathologically, and succeeded in proving the presence of HPV by PCR analysis (HPV 14 in case 1 and HPV 23 and 38 in case 2). All of these detected HPVs belong to genus beta, a group associated with a high risk of carcinogenicity. Although the progression rate of AK to SCC is not so high (estimated at $0.6 \%$ per year [11]), our cases showed rapid progression. It is unclear whether HPV actually induced SCC in our cases, but we think that skin with chronic HPV infection has a greater risk of tumor progression than normal skin. SCC and AK are common diseases; in daily practice, dermatologists examine many patients with immunosuppression of various causes. We should apply increased oncological vigilance to these patients to prevent an aggressive course of SCC/AK.

\section{Statement of Ethics}

The authors have no ethical conflicts to disclose.

\section{Disclosure Statement}

The authors have no conflicts of interest to declare.

\section{References}

1 Hugh M, Gloster HM Jr, Neal K: Skin cancer in skin of color. J Am Acad Dermatol 2006;55:741-760.

-2 Kiviat NB: Papillomaviruses in non-melanoma skin cancer: epidemiological aspects. Semin Cancer Biol 1999;9:397-403.

-3 Wang J, Aldabagh B, Yu J, Arron ST: Role of human papillomavirus in cutaneous squamous cell carcinoma: a meta-analysis. J Am Acad Dermatol 2014;70:621-629.

4 Tommasino M: The human papillomavirus family and its role in carcinogenesis. Semin Cancer Biol 2014;26:13-21.

-5 Aldabagh B, Angeles JG, Cardones AR, Arron ST: Cutaneous squamous cell carcinoma and human papillomavirus: is there an association? Dermatol Surg 2013;39:1-23.

6 Ratushny V, Gober MD, Hick R, Ridky TW, Seykora JT: From keratinocyte to cancer: the pathogenesis and modeling of cutaneous squamous cell carcinoma. J Clin Invest 2012;122:464-472.

7 Shuker N, van Gelder T, Hesselink DA: Intra-patient variability in tacrolimus exposure: Causes, consequences for clinical management. Transplant Rev 2015;29:78-84.

-8 Murao K, Yoshioka R, Kubo Y: Human papillomavirus infection in Bowen disease: negative p53 expression, not p16 (INK4a) overexpression, is correlated with human papillomavirus-associated Bowen disease. J Dermatol 2014;41:878-884. 


\section{Case Reports in Dermatology}

\begin{tabular}{l|l}
\hline \multicolumn{2}{l|}{ Case Rep Dermatol 2015;7:178-182 } \\
\hline DOI: $10.1159 / 000438504$ & $\begin{array}{l}\text { C } 2015 \text { S. Karger AG, Basel } \\
\text { www.karger.com/cde }\end{array}$ \\
\hline
\end{tabular}

Kuma et al.: Two Cases of Cutaneous Squamous Cell Carcinoma Arising in Immunosuppressed Patients with Chronic Human Papillomavirus Infection

9 Viarisio D, Mueller-Decker K, Kloz U, Aengeneyndt B, Kopp-Schneider A, Grone HJ, Gheit T, Flechtenmacher C, Gissmann L, Tommasino M: E6 and E7 from beta HPV38 cooperate with ultraviolet light in the development of actinic keratosis-like lesions and squamous cell carcinoma in mice. PLoS Pathog 2011;7:e1002125.

10 Jung YS, Kato I, Kim HR: A novel function of HPV16-E6/E7 in epithelial-mesenchymal transition. Biochem Biophys Res Commun 2013;435:339-344.

$\checkmark 11$ Criscione VD, Weinstock MA, Naylor MF, Luque C, Eide MJ, Bingham SF: Actinic keratosis: natural history and risk of malignant transformation in the Veterans Affairs Topical Tretinoin Chemoprevention Trial. Cancer 2009;115:2523-2530.

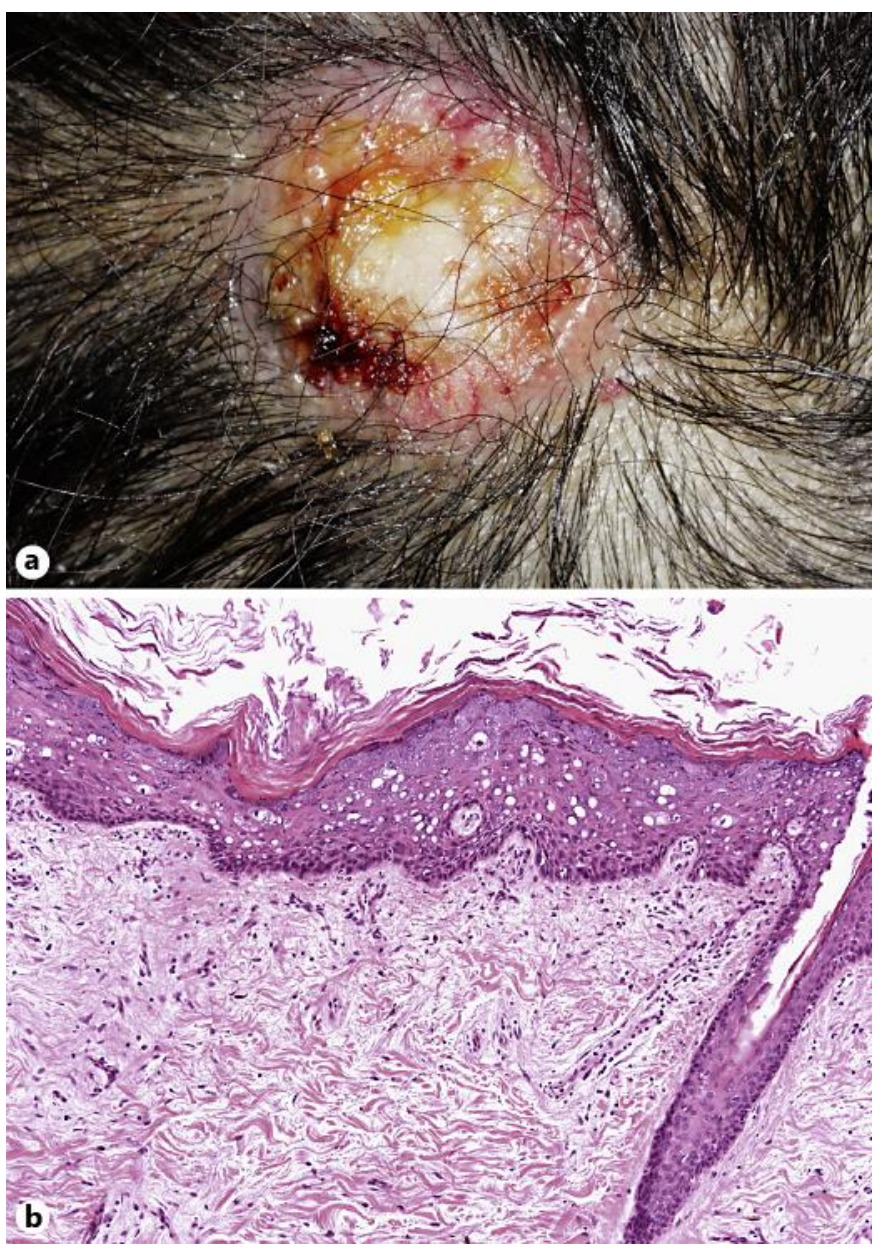

Fig. 1. Case 1. a A red mass on the head. b Biopsy specimen. Note the cytoplasmic vacuolation in the keratinocytes. HE. $\times 100$. 
Kuma et al.: Two Cases of Cutaneous Squamous Cell Carcinoma Arising in Immunosuppressed Patients with Chronic Human Papillomavirus Infection
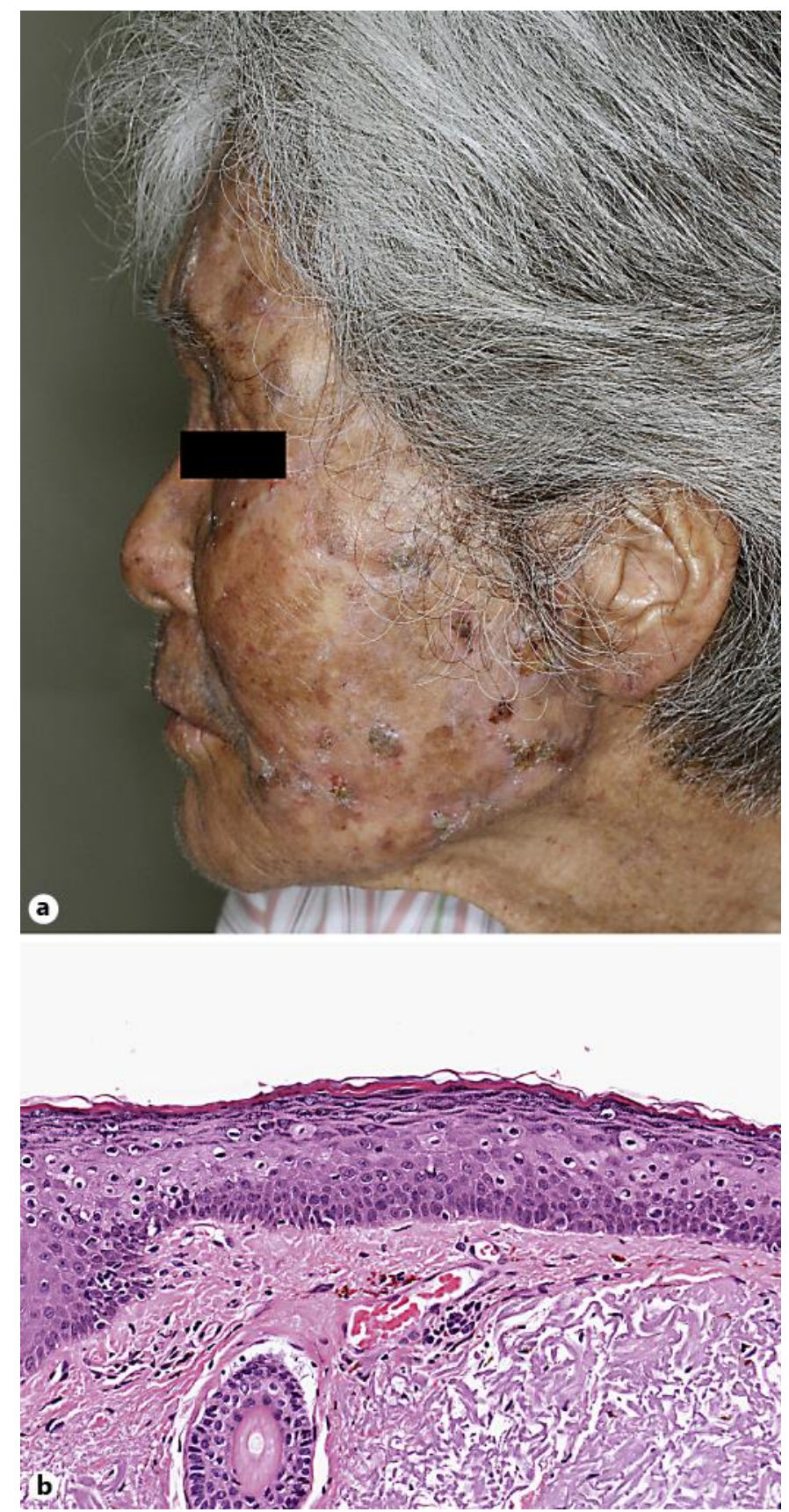

Fig. 2. Case 2. a Disseminated keratotic papules and erythema on the face. b Cytoplasmic vacuolation in the spinous and granular layer. HE. $\times 200$. 